\title{
Polysaccharide/Protein Nanomultilayer Coatings: Construction, Characterization and Evaluation of Their Effect on 'Rocha' Pear (Pyrus communis L.) Shelf-Life
}

\author{
Bartolomeu G. de S. Medeiros • Ana C. Pinheiro • \\ José A. Teixeira • António A. Vicente • \\ Maria G. Carneiro-da-Cunha
}

Received: 15 November 2010 / Accepted: 28 December 2010 /Published online: 21 January 2011

(C) Springer Science+Business Media, LLC 2011

\begin{abstract}
Nanolayered coatings of K-carrageenan, a polysaccharide with good gas barrier properties, and lysozyme, a protein with antimicrobial action, were in a first stage assembled on aminolysed/charged polyethylene terephthalate (PET) pieces, which acted as a support, by alternate five-layer deposition. This was performed to allow the characterization of the nanomultilayer system. PET aminolysis was confirmed by Fourier transform infrared spectroscopy and contact angle, and the subsequent layer adsorption on aminolysed PET surface was confirmed by absorbance, contact angle and SEM images. The water vapour permeability and the oxygen permeability $\left(\mathrm{O}_{2} \mathrm{P}\right)$ of the five layers were found to be $0.013 \pm 0.003 \times 10^{-11}$ and $0.1 \pm 0.01 \times 10^{-14} \mathrm{~g} \mathrm{~m}^{-1} \mathrm{~s}^{-1} \mathrm{~Pa}^{-1}$, respectively. The nanomultilayer system was subsequently applied (without PET support) directly on 'Rocha' (Pyrus communis L.) fresh-cut pears and whole pears. Uncoated fresh-cut pears and whole pears presented higher mass loss, higher total soluble solids (TSS) and lower titratable acidity when compared with coated fresh-cut pears and whole pears. Uncoated fresh-cut pears also presented a darker colour. These results showed
\end{abstract}

B. G. d. S. Medeiros • A. C. Pinheiro • J. A. Teixeira •

A. A. Vicente

IBB-Institute for Biotechnology and Bioengineering,

Centre of Biological Engineering, Universidade do Minho,

Campus de Gualtar,

4710-057 Braga, Portugal

B. G. d. S. Medeiros · M. G. Carneiro-da-Cunha $(\varangle)$ Department of Biochemistry/Keizo Asami Laboratory of Immunopathology, Universidade Federal de Pernambuco, Campus Universitário, $\mathrm{s} / \mathrm{n}$, Cidade Universitaria-CEP,

50.670-420, Recife, Pernambuco, Brazil

e-mail: mgcc@ufpe.br that the nanolayered coating assembled on the fruits' surface has a positive effect on fruit quality and contributed to extend the shelf-life.

Keywords Nanocoatings · Layer-by-layer - K-carrageenan · Lysozyme $\cdot$ Shelf-life $\cdot$ Pear

\section{Introduction}

Nanotechnology offers great potential to food packaging by promising longer shelf-life, safer packaging and healthier food (Neethirajan and Jayas 2011). There are several advantages expected when using a nanotechnological approach in the field of packaging materials, namely in terms of the much lower amounts of functional ingredients needed, the lesser impact in the sensory attributes of foods, and improvements in both mechanical and gas and solutes' transport properties.

Nanomultilayers of polyelectrolytes have been a highly studied class of materials over the past decade due to their potential interest on several fields of application. These materials are obtained by alternating deposition of nanolayers of polyelectrolytes on the surface of a solid substrate, known as layer-by-layer technique. The interaction between the successive layers is mainly due to the electrostatic forces ( $\mathrm{Su}$ and $\mathrm{Li} \mathrm{2008)}$ ) and is central to ensuring the stability of the system.

These nanolayer systems are built aiming at a given set of one or more functionalities. For this reason, the materials selected for each nanolayer must have by themselves specific properties (e.g. antioxidant, antimicrobial and reduction of gas exchange) that justify its use or they must 
show such properties once combined in the nanostructure. The assembly of the nanomultilayer systems can be confirmed, e.g. by UV/VIS spectroscopy, contact angles and scanning electron microscopy (SEM; Carneiro-daCunha et al. 2010; Fu et al. 2005).

K-carrageenan and lysozyme are two potential candidates to be used in the assembly of nanolayered systems. $\mathrm{K}$-carrageenan is a sulphated polyanionic polysaccharide extracted from red algae and is formed by alternating (1-3)D-galactose 4-sulphate and $\alpha(1-4)$ 3,6-anhydro-D-galactose units. Advantages of K-carrageenan such as biocompatibility, biodegradability and absence of toxicity have been pointed out (Schoeler et al. 2006) and confirmed by its extensive use in food, pharmaceutical and cosmetic industries. K-carrageenan has also shown good gas barrier and optical properties (Ribeiro et al. 2007). The lysozyme is an ellipsoidal protein extracted from chicken's eggs, which shows a good resistance to denaturation (Su et al. 1998) and is well known for its antimicrobial properties ( $\mathrm{Su}$ and $\mathrm{Li}$ 2008). Due to its physiological and functional properties, lysozyme has been applied in medicine and in the food industry (Benkerroum 2008).

The quality and the shelf-life of fruits and vegetables are respectively impaired and reduced by several factors such as water loss, enzymatic browning and deterioration of texture. To minimize these alterations, many kinds of packaging materials are being used by the food industry. More recently, consumer concerns on environmental issues have led to the search for biodegradable materials for food packaging applications as replacement of the oil-based polymers traditionally used (Rojas-Graü et al. 2009). In the particular case of fruits, there have been research efforts in the development of edible films and coatings because they may provide not only the extension of shelf-life but may also improve the organoleptic properties. In recent years, edible coatings have been widely studied because of evidence about their beneficial effects on fruits and vegetables (Garcia et al. 2010). However, until now, the potentialities of nanolayered films and coatings have not been exploited at this level.

'Rocha' pear (Pyrus communis L.) is an exclusively Portuguese certified pear cultivar commercialized worldwide in countries like UK, Brazil, France, Ireland, Russia, Poland, the Netherlands, Canada and Spain. Presently, it is also very common to find it cut into pieces or sliced and packaged in small sealed containers for convenience of consumers, which are typically stored under refrigerated conditions.

The aim of this work was the construction and characterization of a nanomultilayer coating system composed of K-carrageenan and lysozyme and the evaluation of its effect on the shelf-life of fresh-cut 'Rocha' pear and whole 'Rocha' pear.

\section{Material and Methods}

\section{Material}

Films of polyethylene terephthalate (PET) were obtained from Canson (Annonay Cedex, France). K-carrageenan was obtained from CPKelco (Genugel WR-78, Lille Skensved, Denmark) and lysozyme was obtained from Sigma-Aldrich (St. Louis, MO, USA). 1,6-Hexanediamine (98\%) and propanol (99.8\%) were obtained from Sigma-Aldrich. Lactic acid $(90 \%)$ and hydrochloric acid were obtained from Merck (Darmstadt, Germany). Ethanol (99.8\%) and sodium hydroxide were obtained from Riedel-de Haën (Seelze, Germany). Semi-mature (titratable acidity $=0.188 \pm 0.008 \%$; total soluble solids $=10.60 \pm 0.30^{\circ}$ Brix; $L^{*}=72.89 \pm 0.91, a=-2.14 \pm 0.45$, $b=44.14 \pm 1.05$ ) pears (cv. Rocha) were purchased at a local retail store (Braga, Portugal).

\section{Preparation of Nanolayered Coating Assembly}

The nanolayered coating was initially built on an aminolysed/charged PET support film. Five alternate polysaccharide and protein nanolayers were adsorbed onto the support with the sequence Carra-Lyso-Carra-Lyso-Carra, where Carra stands for K-carrageenan and Lyso for lysozyme.

\section{Aminolysis of Polyethylene Terephthalate Surface}

PET films were cut into rectangular pieces of $0.8 \times 5.0-\mathrm{cm}$ diameter and circular pieces of $5.0-\mathrm{cm}$ diameter and were aminolysed according to $\mathrm{Fu}$ et al. (2005) as concisely follows. PET films were cleaned in ethanol/water $(1: 1, v / v)$ solution for $3 \mathrm{~h}$, followed by a thorough rinsing with distilled water, and dried at $30{ }^{\circ} \mathrm{C}$ for $24 \mathrm{~h}$. Afterwards, the films were immersed into $0.06 \mathrm{~g} \mathrm{~mL}^{-1}$ 1,6-hexanediamine/ propanol solution at $37^{\circ} \mathrm{C}$ for $4 \mathrm{~h}$, thoroughly washed with distilled water to remove free 1,6-hexanediamine and finally dried at $37^{\circ} \mathrm{C}$ for $24 \mathrm{~h}$. The aminolysed PET films were treated with $0.1 \mathrm{M} \mathrm{HCl}$ solution for $3 \mathrm{~h}$ at room temperature $\left(20{ }^{\circ} \mathrm{C}\right)$, thoroughly washed with distilled water, dried at $30{ }^{\circ} \mathrm{C}$ for $24 \mathrm{~h}$ and termed aminolyzed/ charged PET (A/C PET). This procedure was needed to charge (positively) the otherwise neutral PET surface, aiming at a stronger interaction with the negatively charged K-carrageenan.

\section{Preparation of Polyelectrolyte Solutions}

The $\mathrm{K}$-carrageenan (Carra) solution was prepared by dissolving $0.2 \%(w / v) \quad K$-carrageenan in distilled water under agitation (using a magnetic stirrer) at $200 \mathrm{rpm}$ for $2 \mathrm{~h}$ at $70{ }^{\circ} \mathrm{C}$ and after that for $22 \mathrm{~h}$ at $20^{\circ} \mathrm{C}$. The lysozyme (Lyso) solution was also prepared dissolving $0.2 \%(w / v)$ of 
lysozyme in distilled water under agitation at $200 \mathrm{rpm}$ for $2 \mathrm{~h}$ at $20{ }^{\circ} \mathrm{C}$. The $\mathrm{pH}$ of $\mathrm{K}$-carrageenan and lysozyme solutions was adjusted to $\mathrm{pH} 7.0$ with a solution of $1 \mathrm{M}$ sodium hydroxide and to $\mathrm{pH} 3.8$ with a $1 \mathrm{M}$ lactic acid solution, respectively.

\section{Coating Procedure of A/C PET}

A/C PET pieces were immersed into the Carra solution for $20 \mathrm{~min}$ and subsequently rinsed with deionized water with the same $\mathrm{pH}$ (7.0). The samples were dried by hanging them inside a chamber where nitrogen was gently flown in order to speed up the process. This procedure was repeated with Lyso solution as the polyelectrolyte (except that rinsing was performed with deionized water at $\mathrm{pH} 3.8$ ). This process was repeated with the alternate deposition of a total of five nanolayers. The obtained nanolayered coatings on A/C PET films (A/C PET-Carra-Lyso-Carra-Lyso-Carra) were finally maintained at $20 \pm 2{ }^{\circ} \mathrm{C}$ and $50 \pm 5 \%$ of relative humidity $(\mathrm{RH})$ provided by the laboratory air conditioning system before analysis.

\section{Characterization of Nanolayers}

\section{Fourier Transform Infrared Spectroscopy}

To confirm PET aminolysis, Fourier transform infrared spectroscopy (FTIR) analyses were carried out with a Perkin Elmer 16 PC spectrometer (Perkin Elmer, Boston, MA, USA) equipped with an ATR probe in the wave number region of $600-4,000 \mathrm{~cm}^{-1}$ using 16 scans for each sample.

\section{Zeta Potential}

The zeta potential of the polyelectrolyte solutions was determined by dynamic light scattering (DLS; Zetasizer Nano ZS, Malvern Instruments, UK). Each sample was analysed in a folded capillary cell. Three true replicates were conducted, with three readings for each of them.

\section{UV/VIS Absorbance}

To follow the multilayer assembly, UV/VIS analyses were carried out using a UV/VIS spectrophotometer (Jasco 560, Germany). The absorbance was measured at $296 \mathrm{~nm}$ on the dried films. Three replications of the measurements were taken.

\section{Contact Angle Analysis}

Using the sessile drop method (Newman and Kwok 1999), the contact angles of original PET, A/C PET and the subsequent nanolayers' surface were measured in a face contact angle meter (OCA 20, Dataphysics, Germany). A $2-\mu \mathrm{L}$ droplet of ultrapure water was placed on the horizontal surface with a $500-\mu \mathrm{L}$ syringe (Hamilton, Switzerland) with a needle of $0.75-\mathrm{mm}$ diameter. Measurements were made at 0,15 and $30 \mathrm{~s}$, and for each type of surface, three film samples were used. For each film sample, ten contact angle measurements were carried out at $20 \pm 0.3{ }^{\circ} \mathrm{C}$.

\section{Thickness of Coated A/C PET and of the Nanolayers}

The thickness of A/C PET was measured with a digital micrometer (Mitutoyo, Japan) and confirmed by SEM, and the thickness of each of the five nanolayers was measured by SEM. As a result of the immersion into polyelectrolyte solutions, both sides of the A/C PET pieces were coated with the same set of five layers. Therefore, for the determination of water vapour and oxygen permeability, it was necessary to multiply the thickness value of each of the five layers by 2 .

\section{Water Vapour Permeability}

Based on the ASTM E96-92 method (Casariego et al. 2009), the measurements were carried out gravimetrically. The films were sealed at the top of a permeation cell containing $55 \mathrm{~mL}$ of distilled water $(100 \% \mathrm{RH}$, vapour pressure of 2,337 $\mathrm{Pa}$ at $20^{\circ} \mathrm{C}$ ). The supports were placed in a desiccator at $20{ }^{\circ} \mathrm{C}$ and $0 \%$ of $\mathrm{RH}$ containing silica. The cells were weighed during $10 \mathrm{~h}$ at time intervals of $2 \mathrm{~h}$. The slope of mass loss versus time was achieved by linear regression. Three replicates were obtained for each film and water vapour permeability (WVP) was determined by the following equation (Cooksey et al. 1999):

$\mathrm{WPV}_{b}=\frac{L_{\mathrm{b}}}{\left(\frac{L_{\mathrm{t}}}{\mathrm{WVP}_{t}}\right)-\left(\frac{L_{\mathrm{a}}}{\mathrm{WVP}_{a}}\right)}$

where subscripts $\mathrm{a}, \mathrm{b}$ and $\mathrm{t}$ correspond respectively to: $\mathrm{A} / \mathrm{C}$ PET support (a), nanolayers (Carra-Lyso-Carra-Lyso-Carra) (b) and to the resulting A/C PET support coated with nanolayers (A/C PET-Carra-Lyso-Carra-Lyso-Carra) (t). $L$ corresponds to the thickness of the films (in $\mathrm{mm}$ ) and WVP to the water vapour permeability (in $\mathrm{g} \mathrm{m}^{-1} \mathrm{~s}^{-1} \mathrm{~Pa}^{-1}$ ).

\section{Oxygen Permeability}

Oxygen permeability $\left(\mathrm{O}_{2} \mathrm{P}\right)$ was determined based on ASTM (2002) method. The A/C PET (used as a reference) and the coated A/C PET (A/C PET-Carra-Lyso-Carra-LysoCarra) films were sealed between two chambers, each one with two channels. In the lower chamber, the $\mathrm{O}_{2}$ was supplied at a constant flow rate controlled by a gas flow meter (J\&W Scientific, ADM 2000, USA) to keep its pressure constant in the compartment. The other chamber 
was purged by a stream of nitrogen, also at controlled flow. The nitrogen acted as a carrier for the $\mathrm{O}_{2}$. The flow leaving this chamber was connected to an $\mathrm{O}_{2}$ sensor (Mettler Toledo, Switzerland) which measured the $\mathrm{O}_{2}$ concentration in that flow online. The flows of the two chambers were connected to a manometer to ensure the equality of pressures (both at $1 \mathrm{~atm}$ ) between both compartments. As the $\mathrm{O}_{2}$ was carried continuously by the nitrogen flow, it was considered that the partial pressure of $\mathrm{O}_{2}$ in the upper compartment is null; therefore, $\Delta P$ is equal to $1 \mathrm{~atm}$. Three replicates were obtained for each sample, and the $\mathrm{O}_{2} \mathrm{P}$ for the five nanolayers (CarraLyso-Carra-Lyso-Carra) was determined by the following equation (Cooksey et al. 1999)

$$
\mathrm{O}_{2} P_{b}=\frac{L_{b}}{\left(\frac{L_{\mathrm{t}}}{\mathrm{O}_{2} P_{T}}\right)-\left(\frac{L_{\mathrm{a}}}{\mathrm{O}_{2} P_{a}}\right)}
$$

where $\mathrm{a}, \mathrm{b}$ and $\mathrm{t}$ correspond respectively to: the A/C PET support (a), nanolayers (Carra-Lyso-Carra-Lyso-Carra) (b) and to the resulting coated A/C PET support (A/C PETCarra-Lyso-Carra-Lyso-Carra) (t). $L$ corresponds to the thickness of the films (in $\mathrm{mm}$ ) and $\mathrm{O}_{2} \mathrm{P}$ to the oxygen permeability (in $\mathrm{g} \mathrm{m}^{-1} \mathrm{~s}^{-1} \mathrm{~Pa}^{-1}$ ).

\section{SEM Analysis}

The surface morphology of the studied material was examined using a scanning electron microscope (Nova 130 NanoSEM 200, the Netherlands) with an accelerating voltage from 10 to $15 \mathrm{kV}$. Before analysis, all samples were mounted on aluminium stubs using carbon adhesive tape and sputter-coated with gold (thickness of about $10 \mathrm{~nm}$ ).

Whole and Fresh-Cut Pears Coating and Shelf-Life Evaluation

Twelve pears (cv. Rocha) with uniform size (between 65 and $70 \mathrm{~mm}$ ), uniform colour, absence of physical damage and apparent absence of fungal infection were washed with abundant tap water, left to dry and randomly divided into four groups (two control groups and two test groups) of three pears each. The pears of one control group and of one test group were peeled off, lengthwise sliced in eight pieces and termed fresh-cut pears (CP). The pears of the remaining two groups were termed whole pears (WP). Coating solutions (Carra and Lyso) were applied on test groups of $\mathrm{CP}$ and WP in a similar way as done on the A/C PET surface. The immersion time into each polyelectrolyte solution was 5 and $15 \mathrm{~min}$ for CP and WP test groups, respectively. These immersion times were optimized in preliminary tests. The immersion times for the two control groups of $\mathrm{CP}$ and WP was the same (5 and $15 \mathrm{~min}$, respectively), but distilled water with the respective $\mathrm{pH}$ of
Carra (7.0) and Lyso (3.8) solutions was used instead of the polyelectrolyte solutions used with test groups. After that, all four groups were placed in open plastic boxes and stored at $4{ }^{\circ}$ $\mathrm{C}$ and $93 \% \mathrm{RH}$ (in a temperature- and humidity-controlled room), and the parameters mass loss, total soluble solids, titratable acidity and colour were measured in triplicate over the experimental period of time $(7,14,21$, and 28 days for $\mathrm{CP}$ and $0,1,2,3,5$ and 7 days for WP, respectively).

\section{Mass Loss}

All fresh-cut pears and whole pears were individually weighed at the beginning of the experiment and over the experimental storage time with an analytical balance (METTLER AE200, Mettler Toledo, Germany). The mass loss $(W)$ was expressed as:

$W(\%)=\frac{m_{i}-m_{t}}{m_{i}} \times 100$

where $m_{\mathrm{i}}$ is the initial mass and $m_{t}$ the mass at a certain time $t$.

\section{TSS, TA and Colour Measurement}

Juice samples of CP and of WP were obtained using a domestic juice extractor (Moulinex Mx type 664, Spain) and collected in sterilized jars in aseptic conditions. The total soluble solids (TSS) were determined on this juice using a refractometer (SCHMIDT+HAENSCH, GmbH \& Co., series no. 4008).

Titratable acidity was determined by titrating $10 \mathrm{~g}$ of pear flesh liquefied with $100 \mathrm{~mL}$ of distilled water (Becken max mix II, Spain) with $0.1 \mathrm{~N} \mathrm{NaOH}$ solution (Instituto Adolfo Lutz 1985). The results were expressed as per cent $(w / w)$.

The surface colour was measured throughout the experimental storage period using a colorimeter (CR 400; Minolta, Japan) and evaluated through the changes of $L^{*}$ values. Three readings were made on randomly chosen reading positions for each sample.

\section{Statistical Analyses}

The statistical analyses were carried out using analysis of variance, Tukey mean comparison test $(p<0.05)$ and linear regression analysis (SigmaStat, trial version, 2003, USA).

\section{Results and Discussion}

\section{Aminolysis on PET Support}

FTIR analyses were carried out to confirm the presence of amino groups on the A/C PET surface. Figure 1 shows two differences between the $\mathrm{A} / \mathrm{C}$ PET and the original PET, 


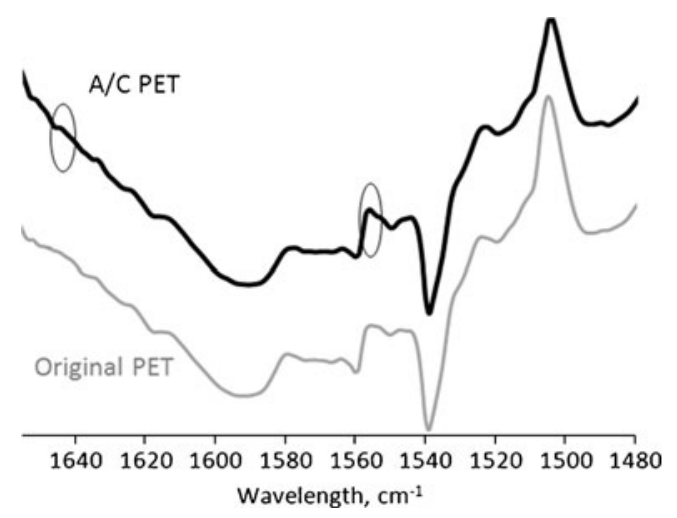

Fig. 1 Raw data of FTIR spectra of A/C PET (black line) and of original PET (grey line). Circles show the differences corresponding to the amide I and II groups on aminolysed PET surface

located at 1,647 and $1,558 \mathrm{~cm}^{-1}$, which confirm that the Original PET was successfully aminolysed. Similar results were reported by $\mathrm{Fu}$ et al. (2005), and working with the same aminolysed PET, Carneiro-da-Cunha et al. (2010) confirmed the presence of a nitrogen peak through energydispersive spectroscopy.

\section{Zeta Potential}

Aminolysed PET samples were purposely treated with $\mathrm{HCl}$ to charge positively the support surface. The first negatively charged layer ( $\mathrm{K}$-carrageenan) will interact with the support surface by electrostatic forces and the subsequent lysozyme layer (positively charged) will interact with the K-carrageenan's oppositely charged surface. In order to ensure that the interaction between the polyelectrolyte solutions and the A/C PET surface would be sufficiently strong, the $\mathrm{pH}$ values of polyelectrolyte solutions were previously adjusted to obtain the adequate charges. The $\mathrm{pH}$ values were determined based on K-carrageenan's dissociation constant ( $\mathrm{p} K_{\mathrm{a}}=2.0$; Jones et al. 2010) and lysozyme's isoelectric point ( $\mathrm{p} I=11$; Lvov et al. 1995).

The electrostatic properties were confirmed by the determination of the solutions' zeta potential by DLS. The lowest zeta potential value of $-60.53 \pm 0.15 \mathrm{mV}$ was found for $\mathrm{k}$-carrageenan at $\mathrm{pH}$ 7.0. The same $\mathrm{pH}$ value was used by Schoeler et al. (2006) when preparing ultrathin films with one cationic poly(allylamine hydrochloride) and two anionic polysaccharides, $\lambda$ - and -carrageenan. These ultrathin films were compared with the films assembled at $\mathrm{pH} \mathrm{10.0,} \mathrm{and} \mathrm{the} \mathrm{authors} \mathrm{found} \mathrm{that} \mathrm{the} \mathrm{thickness} \mathrm{of} \mathrm{the}$ films assembled at $\mathrm{pH} 7.0$ was lower than the films assembled at $\mathrm{pH} 10.0$. The highest zeta potential value of $+25.67 \pm 2.27 \mathrm{mV}$ was found for lysozyme at $\mathrm{pH}$ 3.8. A similar $\mathrm{pH}$ value was used by Lvov et al. (1995).

The charge of some polysaccharides may be associated with the number of sulphate groups in their structure. This is possibly the case of K-carrageenan (Reynaers 2003), putting it in position to be a good candidate for electrostatic interactions.

\section{UV/VIS Absorbance}

The layers' deposition was followed measuring the increase in absorbance at $296 \mathrm{~nm}$, the wavelength at which the highest absorbance peak was found. The increase in absorbance due to the layer's deposition (Fig. 2a) is in agreement with other works where deposition through layer-by-layer technique was characterized by UV/VIS spectroscopy (Carneiro-daCunha et al. 2010; Fu et al. 2005). These results confirm the successful assembly of the nanolayered film.

\section{Contact Angle}

The values of contact angles observed on the original PET, $\mathrm{A} / \mathrm{C}$ PET support and on the five successive layers added are shown in Fig. 2b. The global trend is not affected by the time of observation after drop application. After 15 and
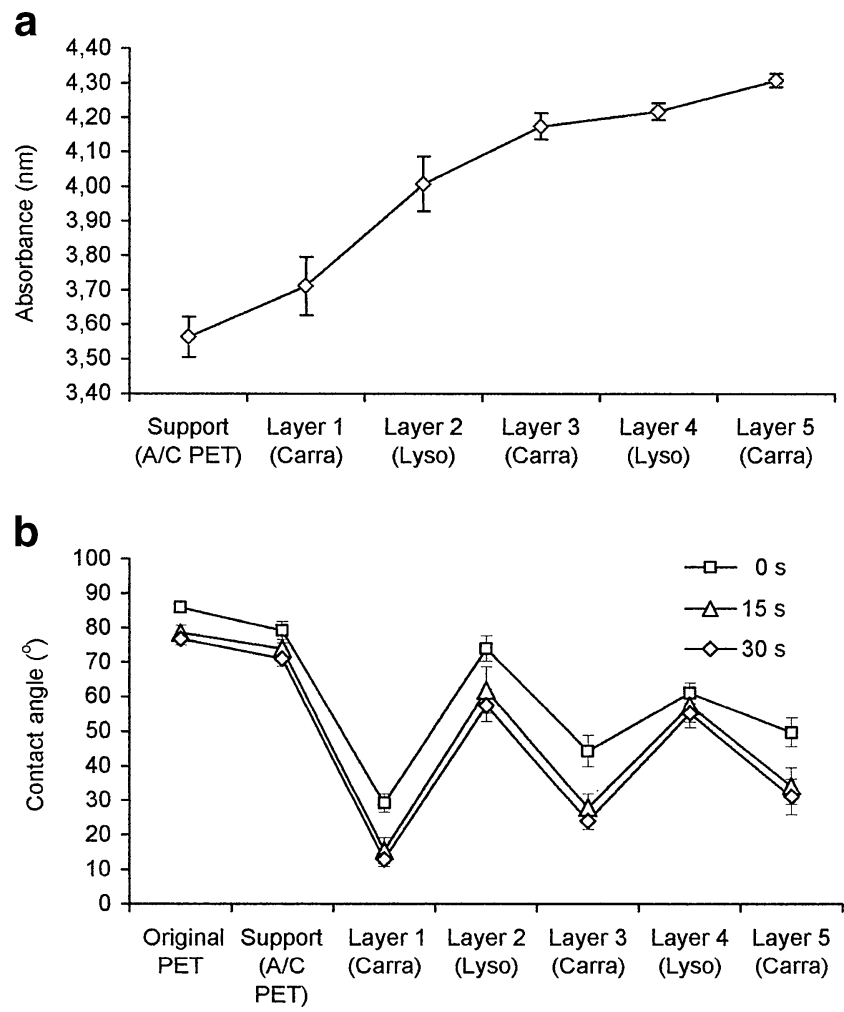

Fig. 2 a UV/VIS spectroscopy analysis at $296 \mathrm{~nm}$ of A/C PET support and after the addition of each of the five successive layers containing K-carrageenan (Carra) and lysozyme (Lyso). Each data point is the average of nine determinations; error bars show the standard deviation. b Contact angle measured on original PET, A/C PET support and on each of the five successive layers containing $\mathrm{K}$ carrageenan (Carra) and lysozyme (Lyso) after 0, 15 and $30 \mathrm{~s}$ of drop application. Each data point is the average of 30 measurements; error bars show the standard deviation 
$30 \mathrm{~s}$, the results are similar; therefore, $15 \mathrm{~s}$ was taken as the reference time.

The hydrophobicity of original PET was confirmed by the contact angle of $78.55 \pm 1.7^{\circ}$, and the value of the contact angle of the $\mathrm{A} / \mathrm{C}$ PET of $73.93 \pm 1.72^{\circ}$ is lower than the original PET, being in agreement with Carneiro-daCunha et al. (2010). From this behaviour, one can deduce that the aminolysis of PET surface was well performed, corroborating the result from the FTIR analyses.

The magnitude of contact angles illustrated in Fig. 2b shows the evolution of the alternate deposition of $\mathrm{k}$-carrageenan and lysozyme layers, suggesting that the film was progressively assembled by alternate deposition of the polyelectrolytes. The angles with small magnitude were observed for the layers assembled at $\mathrm{pH} 7.0$ and with great magnitude obtained for the layers assembled at $\mathrm{pH}$ 3.8. Small contact angles ( $\mathrm{K}$-carrageenan layer) define a hydrophilic surface and great contact angles (lysozyme layer) characterize a hydrophobic surface. The hydrophobic character of lysozyme layers was confirmed in our work with the contact angles ranging from $61.85 \pm 6.63^{\circ}$ to $57.48 \pm 4.82^{\circ}$ in comparison with the contact angles of $\mathrm{K}$-carrageenan layers (from $15.47 \pm 3.65^{\circ}$ to $34.20 \pm$ $\left.5.27^{\circ}\right)$. It is possible that segments of chemical structure of an underlying layer penetrate into the surface of the outmost layer, when they differ from each other in thickness and one is positively charged and the other negatively charged, thus changing its hydrophobicity or hydrophilicity (Yoo et al. 1998). The most wettable surfaces present lower values of contact angles, and on the contrary, the hydrophobic surfaces show higher values. The wettability of a surface depends on the nature of the outermost layer and not only on the initial or previous substrate. The interpenetration of the layers may influence this property (Yoo et al. 1998), especially at the nanoscale. The wettability of a surface can be significantly affected by changes of $\mathrm{pH}$ since they can affect the structure itself.

\section{Scanning Electron Microscopy}

The SEM images were captured to observe the A/C PET surface and the A/C PET support with all five layers already adsorbed (Fig. 3). Figure 3a, b shows the A/C PET before layer deposition and the outmost surface of the five layers already adsorbed on A/C PET, respectively. Figure $3 \mathrm{c}$ shows the five layers of the two polyelectrolytes, $\mathrm{K}$-carrageenan and lysozyme. These images confirm the construction of the nanolayered film on the PET surface.

\section{Water Vapour Permeability}

Shelf-life and food quality can be improved by edible films and coatings (Cerqueira et al. 2009; Souza et al. 2010), providing a good and selective barrier to the moisture
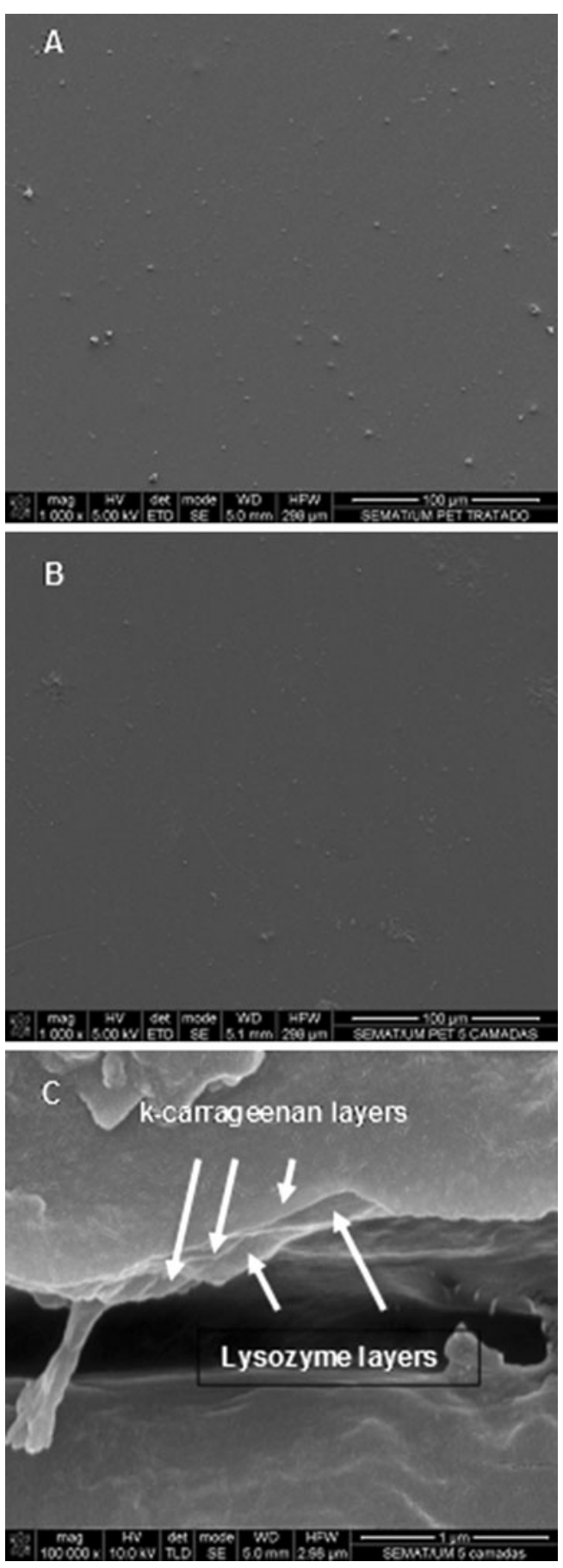

Fig. 3 Scanning electron microscopy images of surface morphology of A/C PET (a), outmost surface of the five layers (b) and crosssection of the five nanolayers (c) (scale bar, $1 \mu \mathrm{m}$ )

transfer, oxygen uptake, lipid oxidation, losses of volatile aromas and flavours. On the other hand, films or coatings made of polysaccharides or proteins are reported to provide high gas barrier properties (Miller and Krochta 1997).

Using Eq. 1 and the A/C PET thickness value of $0.103 \mathrm{~mm}$, measured with a micrometer and confirmed by SEM, and the five layers thickness value of $469.2 \mathrm{~nm}$, 
obtained by SEM, the WVP values determined for $\mathrm{A} / \mathrm{C}$ PET and for the five nanolayers were $1.51 \pm 0.07 \times 10^{-11}$ and $0.013 \pm 0.003 \times 10^{-11} \mathrm{~g} \mathrm{~m}^{-1} \mathrm{~s}^{-1} \mathrm{~Pa}^{-1}$, respectively. The WVP value obtained for the multilayer film was much lower than those that could be expected for edible films composed of carrageenan and lysozyme. The reported values in literature for carrageenan $( \pm 50 \mu \mathrm{m}$ of thickness $)$ and lysozyme $( \pm 70 \mu \mathrm{m}$ of thickness $)$ films are $232.0 \pm 9.9 \times$

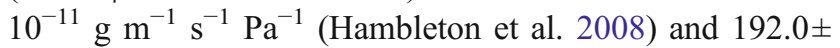
$25.7 \times 10^{-11} \mathrm{~g} \mathrm{~m}^{-1} \mathrm{~s}^{-1} \mathrm{~Pa}^{-1}$ (Park et al. 2004), respectively. The good water vapour permeability of the five nanolayers may be explained based on the hydrophobic amino acid chains of lysozyme that may contribute to the decrease of the hydrophilicity of the K-carrageenan/lysozyme nanolayers and on interactions that are established between adjacent $\mathrm{K}$-carrageenan and lysozyme layers that increase the tortuosity of the material, thus decreasing its effective permeability to the water molecules (Jang et al. 2008).

Since the WVP value of the five nanolayers was lower than that found for A/C PET, it can be concluded that the nanolayers of Carra and Lyso provide a good water barrier. The WVP value found in this work is of the same order of magnitude for the five nanolayers composed of alginate and chitosan $\left(0.009 \times 10^{-11} \mathrm{~g} \mathrm{~m}^{-1} \mathrm{~s}^{-1} \mathrm{~Pa}^{-1}\right)$ found by Carneiroda-Cunha et al. (2010). Oms-Oliu et al. (2008) applied different polysaccharide-based coatings on fresh-cut pieces of pears P. communis L. (cv Flor de Invierno) and observed a substantial increase of water vapour transport resistance.

\section{Oxygen Permeability}

Another parameter to take into account in the shelf-life of fruits and vegetables is oxygen permeability $\left(\mathrm{O}_{2} \mathrm{P}\right)$. A reduction of the oxygen flow rate promotes a reduction of oxidation. $\mathrm{O}_{2} \mathrm{P}$ of edible films and coatings depend on several factors such as the integrity of the film, the ratio between crystalline and amorphous zones, the hydrophilic/hydrophobic ratio, and the chain mobility (Miller and Krochta 1997).

Using Eq. 2 and the thickness values previously determined, an $\mathrm{O}_{2} \mathrm{P}$ value of $2.5 \pm 0.03 \times 10^{-14} \mathrm{~g} \mathrm{~m}^{-1} \mathrm{~s}^{-1} \mathrm{~Pa}^{-1}$ was obtained for A/C PET and a lower $\mathrm{O}_{2} \mathrm{P}$ value of $0.1 \pm 0.01 \times$ $10^{-14} \mathrm{~g} \mathrm{~m}^{-1} \mathrm{~s}^{-1} \mathrm{~Pa}^{-1}$ was obtained for the five nanolayers, meaning that the nanolayers exhibit a significant barrier against $\mathrm{O}_{2}$ flow. Conventional edible films composed of K-carrageenan exhibited significantly higher values of $\mathrm{O}_{2} \mathrm{P}$ : $5.95 \pm 0.94 \times 10^{-9} \mathrm{~g} \mathrm{~m}^{-1} \mathrm{~s}^{-1} \mathrm{~Pa}^{-1}$ (Ribeiro et al. 2007) and $0.72 \pm 0.28 \times 10^{-11} \mathrm{~g} \mathrm{~m}^{-1} \mathrm{~s}^{-1} \mathrm{~Pa}^{-1}$ (Hambleton et al. 2008). These good results for the multilayer nanofilm may again be explained based on the interactions that are established between adjacent $\mathrm{k}$-carrageenan and lysozyme layers. In fact, polysaccharide- and protein-based coatings or films are usually characterized, among other things, for having low oxygen permeability values (Lima et al. 2010).

\section{Evaluation of Pear Shelf-Life}

Taking into account the economical importance of pears in natura and, more recently, the appearance of an important market of semi-processed fresh-cut fruits, nanolayers of K-carrageenan/lysozyme were applied on the pears' surface (fresh-cut pears and whole pears) aiming at knowing how this coating may extend their shelf-life. For such a purpose, physicochemical analyses were carried out and the results of coated CP and WP were compared with those obtained with uncoated (control) fruits.

\section{Mass Loss}

The modified atmosphere created by edible coatings (between the coating and the fruit's surface) protects the fruits from the moment it is applied until they reach the final consumer (Ribeiro et al. 2007; Souza et al. 2010). The mass loss occurs manly due to water loss since the other components that can be lost (e.g. aromas, flavours and gaseous products of respiration) are practically undetectable in terms of mass (Olivas and Barbosa-Cánovas 2005).

For that very reason, the mass loss of coated fresh-cut pears and coated whole pears with $\mathrm{k}$-carrageenan/lysozyme nanolayers was followed over the experimental storage period to determine how effective this coating was as a barrier against water loss.

The fruits' skin is a good barrier against chemical and physical damage and prevents microbial growth (MartínBelloso et al. 2006). Lysozyme was incorporated in the nanolayer structure due to its well-known antimicrobial properties (Gemili et al. 2009; Mecitoğlu et al. 2006) and to protect mainly the fresh-cut pears against microbial action.

Over an experimental storage period of 7 days (Fig. 4a) and 45 days (Fig. 4b) of CP and of WP, respectively, there are statistically significant differences $(p<0.05)$ between uncoated fresh-cut pears and whole pears (control groups) and coated fresh-cut pears and whole pears (test groups). On the other hand, the magnitude of mass loss between the fresh-cut pears and the whole pears is not the same, as can be observed comparing Fig. 4a, b.

At the end of the seventh day of storage (Fig. 4a), the mass loss of fresh-cut pears was found to be $13.3 \pm 1.3 \%$ and $3.5 \pm 0.6 \%$ for uncoated (control group) and coated (test group) fruits, respectively, which demonstrates the effectiveness of the nanolayers as a water loss barrier.

The same behaviour was found for whole pears (Fig. 4b). On the 45th day of storage, uncoated (control group) and coated (test group) fruits presented a mass loss of $1.4 \pm 0.19 \%$ and $0.8 \pm 0.02 \%$, respectively. These differences can be mostly related with the water vapour barrier provided by the coating, leading to a lower water loss and, consequently, to a lower mass loss. 

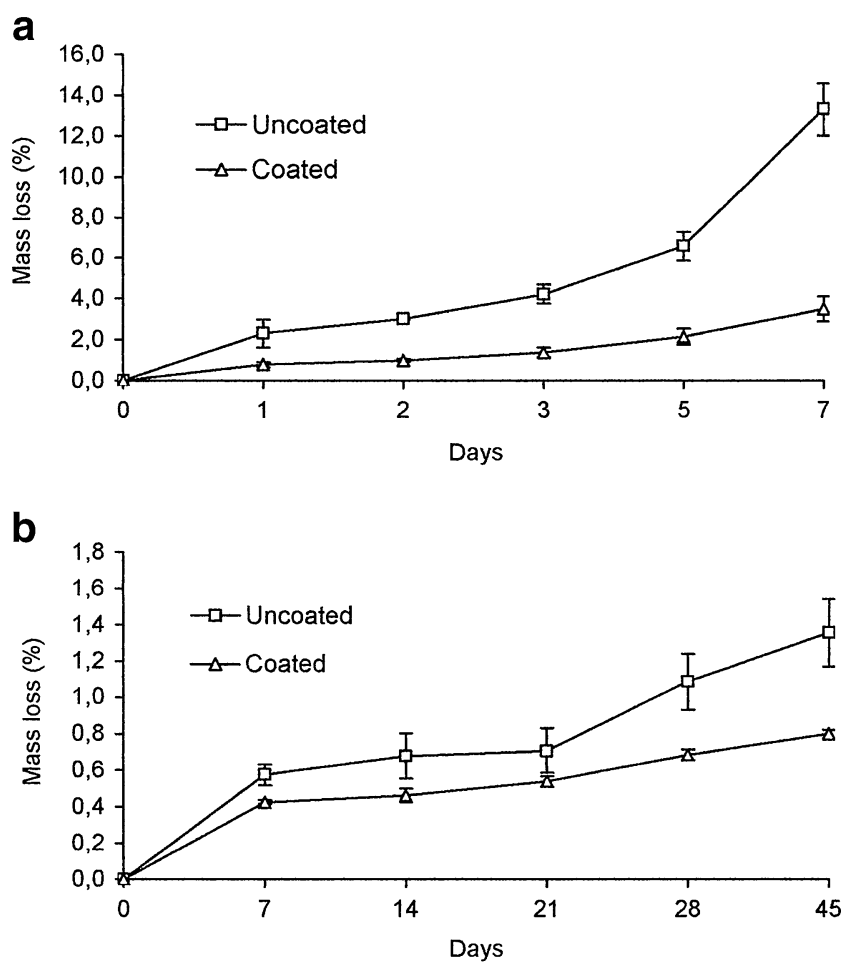

Fig. 4 Mass loss of fresh-cut pear over 7 days (a) and of whole pears over 45 days (b). Each data point is the average of three determinations and the error bars show the standard deviation

It is known that the skin of the fruits protects against water loss and pathogen invasion and provides partial barrier to gases; therefore, the mass loss observed after 45 days of storage for whole pears is much lower than that for fresh-cut pears after 7 days of storage.

\section{Total Soluble Solids}

Total soluble solids (TSS) represent water-soluble substances like sugars, acids, vitamin $\mathrm{C}$ and some pectins (Oliveira et al. 1999), and since sugar corresponds to $90 \%$ of TSS, this parameter is used as an indicator of total sugar content and maturation stage of the fruit.

At the beginning of the experimental period (day 0), both fresh-cut pears (Fig. 5a) and whole pears (Fig. 5b) had a TSS with a ${ }^{\circ}$ Brix value of similar level (between $10.20 \pm 0.45$ and $10.86 \pm 0.06^{\circ}$ Brix) and without statistically significant differences $(p>0.05)$; these values are in agreement with those found by Nicolaï et al. (2008) (between 10.4 and $15.4^{\circ}$ Brix), also for pears. The TSS content in fruits increases during the maturation phase due to metabolic processes. When water loss occurs, there is also an increase of TSS essentially due to the increase of the concentration of sugar in the fruits (Bhattarai and Gautam 2006). Both for uncoated fresh-cut pears (Fig. 5a) and for uncoated whole pears (Fig. 5b), TSS increased until the 5th and 28th days, respectively, and diminished at the end of the experimental period to similar levels $(p>0.05)$. This
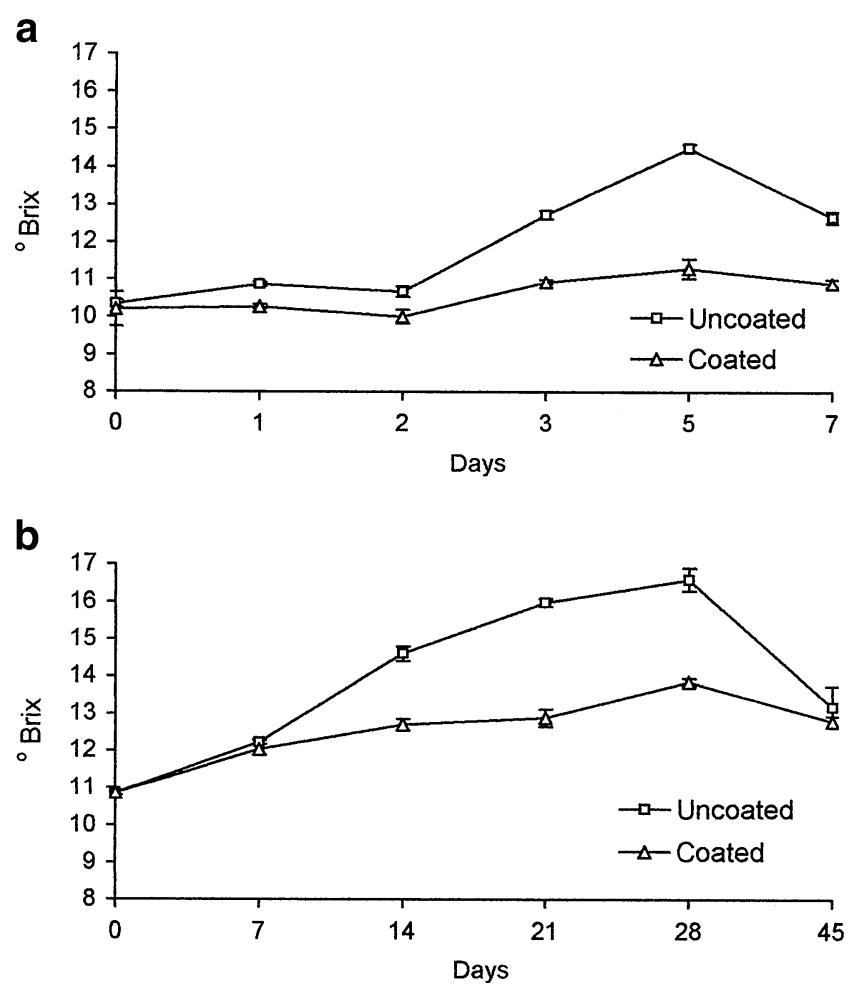

Fig. 5 Total soluble solids (TSS) of fresh-cut pears over 7 days (a) and of whole pears over 45 days (b). Each data point is the average of three determinations; error bars show the standard deviation

decrease is probably related to the slowing down of polysaccharide degradation reactions and the corresponding consumption of the resulting sugars by the living tissue of the fruits. Although with a similar profile, TSS values remained lower for both coated fresh-cut pears and coated whole pears throughout the respective experimental period. At the end of the experiment (days 7 and 45, respectively), the coated fresh-cut pears exhibited a TSS value significantly lower $(p<0.05)$ than the control pears; however, for whole pears, a statistically significant difference $(p>0.05)$ was not found between uncoated and coated groups.

The generally lower values of TSS for the coated fruits are a direct result of the barrier to water vapour mass transfer imposed by the coating. Also, the decreased $\mathrm{O}_{2}$ and $\mathrm{CO}_{2}$ transfer rate due to the presence of the coating will impose a reduction in the metabolic activity of the fruits, thus leading to a further slowdown of polysaccharide degradation reactions and, therefore, to a lower TSS value for the coated fruits. In any case, the values of $\mathrm{O}_{2}$ permeability obtained here are sufficiently high to ensure that no danger of anaerobiosis is at stake.

\section{Titratable Acidity}

Titratable acidity is another parameter that changes with the maturity phase due to organic acids that are usually consumed during the fruits' shelf-life. 
The final organic acid content of the fruit is determined by the net balance of acid synthesis, degradation, utilization and compartmentalization (Müller et al. 1996).

At the beginning of the experimental period, TA values of both fresh-cut pears (Fig. 6a) and whole pears (Fig. 6b) were around $0.20 \%$ and decreased until the end of both experimental periods (7th and 45th days, respectively). Silva et al. (2010) obtained values within the range from $0.28 \%$ to $0.14 \%$ for 'Rocha' pears at different stages of maturation during storage at $-0.5{ }^{\circ} \mathrm{C}$ for 250 days. Although the four groups of samples showed a decrease over the experimental period, the test groups exhibited significantly higher $(p<0.05)$ TA values than the control.

The decrease of acidity with maturation during cold storage of 'Rocha' pear was characterized by Galvis-Sánchez et al. (2004). Kingston (1993) determined the maturity indices for apples and pears, concluding that as the maturation goes on, there is a decrease of TA until it stabilizes at the end. According to Toğrul and Arslan (2004), the decrease in titratable acidity may be due to the breakup of acids present in fruit to sugars with respiration during storage.

The lower reduction of TA values of coated $\mathrm{CP}$ and coated WP suggests that the maturation of test groups was retarded by the application of the nanolayer coating as compared to control (uncoated) groups due to reduced gas $\left(\mathrm{O}_{2}\right.$ and $\left.\mathrm{CO}_{2}\right)$ exchange owing to the presence of the coating.
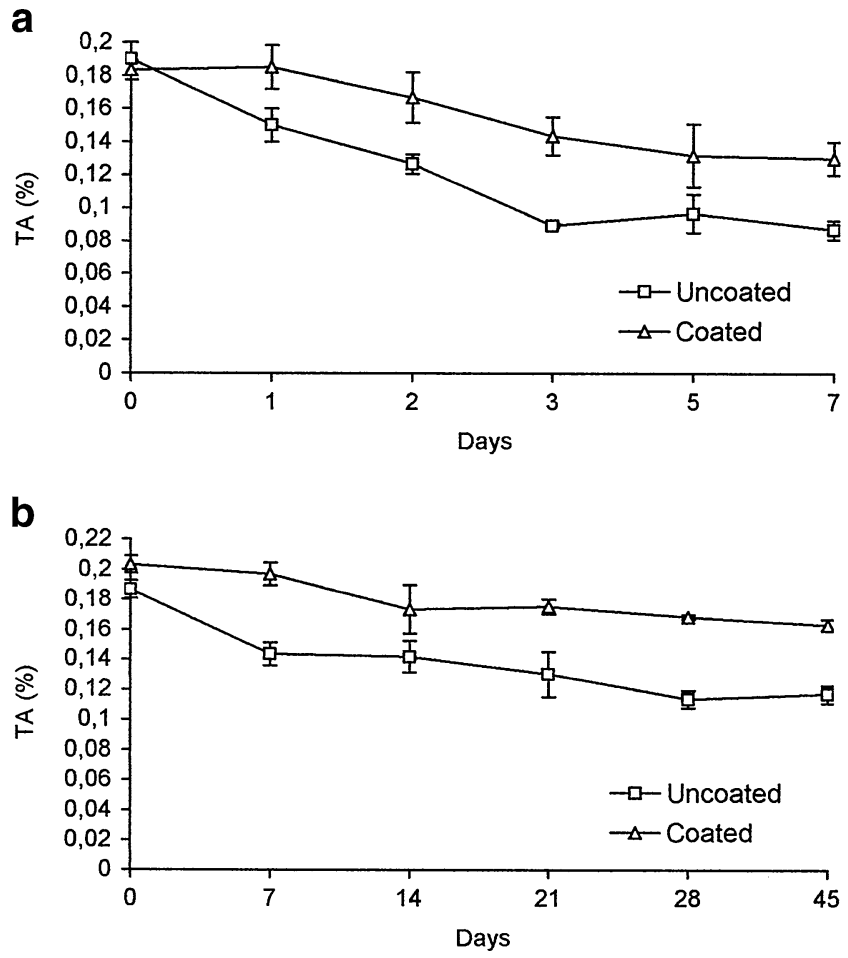

Fig. 6 Titratable acidity (TA) of fresh-cut pears over 7 days (a) and of whole pears over 45 days (b). Each data point is the average of three determinations; error bars show the standard deviation

\section{Colour}

Darkening of fruits is the result of oxidation processes that occur at advanced maturation stages, and the changes of colour can be evaluated through the $L^{*}$ parameter that measures lightness.

The fruit's skin is a natural protection against environmental attacks. During the experimental period of 45 days, uncoated and coated whole pears did not present significant differences of $L^{*}$. Uncoated whole pears presented a reduction of $8.0 \%$, whilst coated whole pears showed a reduction of $4.6 \%$ for this parameter. However, the $L^{*}$ values of uncoated fresh-cut pears decreased throughout the 7 days of the experimental period: From an initial value of $66.3 \pm$ 2.4, a final value of $43.7 \pm 6.1$ was attained. Coated fresh-cut pears exhibited a completely different behaviour, and no significant changes in $L^{*}(p>0.05)$ were observed during the experimental period ( $L^{*}$ varied from $70.0 \pm 1.2$ at days 0 to $65.9 \pm 5.3$ at day 7). Similar results were obtained by Abreu et al. (2003) for 'Rocha' fresh-cut pears pretreated at $40{ }^{\circ} \mathrm{C}$ for $105 \mathrm{~min}$ and subsequently stored at $2{ }^{\circ} \mathrm{C}$ during 7 days.

Lower values of $L^{*}$ are a consequence of darkening, which occurs mainly due to the increase of respiration and enzymatic processes, causing quality loss of the fruit. When pears are cut, the tissue cells are broken and enzymes, such as polyphenol oxidase, are liberated and brought into contact with their substrates, causing browning (Olivas et
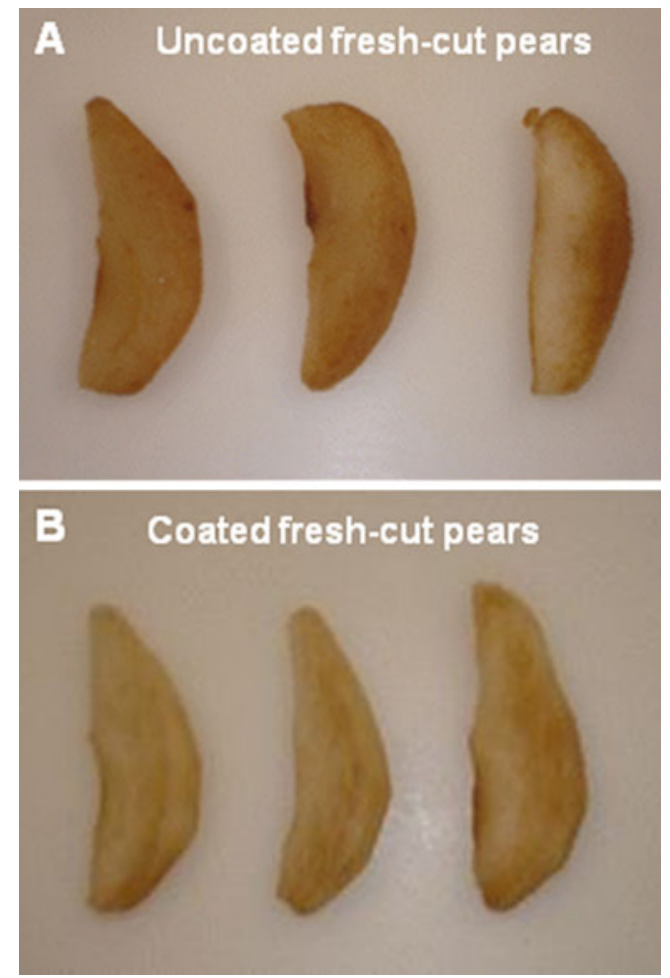

Fig. 7 Images of uncoated (a) and coated (b) fresh-cut pears on the seventh day of storage 
al. 2007). The reduction of the oxidation process may have occurred in the present work in coated fresh-cut pears and coated whole pears. Uncoated fresh-cut pears, as exhibited in the Fig. 7a, presented a brownish colour in comparison with coated fresh-cut pears (Fig. 7b).

\section{Conclusion}

The work presented here has established the proof-of-concept of the use of nanolayered edible coatings for food preservation. Such coatings have adequate mass transfer properties (the WVP), and the $\mathrm{O}_{2} \mathrm{P}$ of the five nanolayers was found to be $0.013 \pm 0.003 \times 10^{-11}$ and $0.1 \pm 0.01 \times 10^{-14} \mathrm{~g} \mathrm{~m}^{-1} \mathrm{~s}^{-1} \mathrm{~Pa}^{-1}$, respectively) and adequate surface properties (measured in terms of contact angles) to be used as packaging materials for 'Rocha' pears.

As a result of this, uncoated fresh-cut pears and whole pears presented higher mass loss, higher TSS and lower TA when compared with coated fresh-cut pears and whole pears. Uncoated fresh-cut pears also showed a darker colour. These findings suggest that the nanolayered coating of $k$-carrageenan and lysozyme assembled on the pears' surface had a significant positive effect on the quality of the fruits and therefore hold potential for their shelf-life extension.

Acknowledgments Author Bartolomeu G. de S. Medeiros was a recipient of a scholarship from the project Isac (Isac Mundus Cooperation, European Union) and is also a recipient of a scholarship from Coordenação de Aperfeiçoamento de Pessoal de Nível Superior (Capes, Brazil). Author A.C. Pinheiro is recipient of a fellowship (SFRH/BD/48120/2008) from the Fundação para a Ciência e Tecnologia (FCT, Portugal).

\section{References}

Abreu, M., Beirão-da-Costa, S., Gonçalves, E. M., Beirão-da-Costa, M. L., \& Moldão, M. (2003). Use of mild heat pre-treatments for quality retention of fresh-cut 'Rocha' pear. Postharvest Biology and Technology, 30(2), 153-160.

ASTM D 3985-02 (2002) Standard test method for oxygen gas transmission rate through plastic film and sheeting using a coulometric sensor. ASTM Book of Standards, 15.09.

Benkerroum, N. (2008). Antimicrobal activity of lysozyme with special relevance to milk review. African Journal of Biotechnology, 7(25), 4856-4867.

Bhattarai, D. R., \& Gautam, D. M. (2006). Effect of harvesting method and calcium on post harvest physiology of tomato. Nepal Agriculture Research Journal, 7, 37-41.

Carneiro-da-Cunha, M. G., Cerqueira, M. A., Souza, B. W. S., Carvalho, S., Quintas, M. A. C., Teixeira, J. A., et al. (2010). Physical and thermal properties of a chitosan/alginate nanolayered PET film. Carbohydrate Polymers, 82(1), 153-159.

Casariego, A., Souza, B. W. S., Cerqueira, M. A., Teixeira, J. A., Cruz, L., Díaz, R., et al. (2009). Chitosan/clay films' properties as affected by biopolymer and clay micro/nanoparticles' concentrations. Food Hydrocolloids, 23(7), 1895-1902.
Cerqueira, M. A., Lima, A. M., Souza, B. W. S., Teixeira, J. A., Moreira, R. A., \& Vicente, A. A. (2009). Functional polysaccharides as edible coatings for cheese. Journal of Agriculture and Food Chemistry, $57,1456-1462$.

Cooksey, K., Marsh, K. S., \& Doar, L. H. (1999). Predicting permeability \& transmission rate for multilayer materials. Food Technology, 53(9), 60-63.

Fu, J., Ji, J., Yuan, W., \& Shen, J. (2005). Construction of antiadhesive and antibacterial multilayer assembly of heparin and chitosan. Biomaterials, 26, 6684-6692.

Galvis-Sánchez, A. C., Fonseca, S. C., Morais, A., \& Malcata, F. X. (2004). Sensorial and physicochemical quality responses of pears (cv Rocha) to long-term storage under controlled atmospheres. Journal of the Science of Food and Agriculture, 84(13), 1646-1656.

Garcia, L. C., Pereira, L. M., Sarantópoulos, C. I. G. L., \& Hubinger, M. D. (2010). Selection of an edible starch coating for minimally processed strawberry. Food and Bioprocess Technology, 3, 834-842.

Gemili, S., Yemenicioğlu, A., \& Altınkaya, S. A. (2009). Development of cellulose acetate based antimicrobial food packaging materials for controlled release of lysozyme. Journal of Food Engineering, 90, 453-462.

Hambleton, A., Debeaufort, F., Beney, L., Karbowiak, T., \& Voilley, A. (2008). Protection of active aroma compound against moisture and oxygen by encapsulation in biopolymeric emulsion-based edible films. Biomacromolecules, 9(3), 1058-1063.

Instituto Adolfo Lutz. (1985). Normas analiticas: Métodos químicos e fisicos para análises de alimentos, 3rd ed., vol. 1. São Paulo, Brazil, p. 533.

Jang, S. G., Choi, D.-G., Heo, C.-J., Lee, S. Y., \& Yang, S.-M. (2008). Nanoscopic ordered voids and metal caps by controlled trapping of colloidal particles at polymeric film surfaces. Advanced Materials, 20, 4862-4867.

Jones, O., Decker, E. A., \& McClements, D. J. (2010). Thermal analysis of $\beta$-lactoglobulin complexes with pectins or carrageenan for production of stable biopolymer particles. Food Hydrocolloids, 24, 239-248.

Kingston, C. M. (1993). Maturity indices for apple and pear. Horticultural Reviews, 13, 407-432.

Lima, A. M., Cerqueira, M. A., Souza, B. W. S., Santos, E. C. M., Teixeira, J. A., Moreira, R. A., et al. (2010). New edible coatings composed of galactomannans and collagen blends to improve the postharvest quality of fruits-Influence on fruits gas transfer rate. Journal of Food Engineering, 97, 101-109.

Lvov, Y., Ariga, K., Ichinose, I., \& Kunitake, T. (1995). Assembly multicomponent protein films by means of electrostatic layer-bylayer adsorption. Journal of the American Chemical Society, 117, 6117-6123.

Martín-Belloso, O., Soliva-Fortuny, R., \& Oms-Oliu, G. (2006). Fresh-cut fruits. In Y. H. Hui (Ed.), Handbook of fruits and fruit processing. Iowa: Blackwell.

Mecitoğlu, C.., Yeminicioğlu, A., Arslanoğlu, A., Elmaci, Z. S., Korel, F., \& Çetin, A. E. (2006). Incorporation of partially purified hen egg white lysozyme into zein films for antimicrobial food packaging. Food Research International, 39, 12-21.

Miller, K. S., \& Krochta, J. M. (1997). Oxygen and aroma barrier properties of edible films: A review. Trends in Food Science and Technology, 8(7), 228-237.

Müller, M. L., Irkens-Kiesecker, U., Rubinstein, B., \& Taiz, L. (1996). One the mechanism of hyperacidification in lemon. The Journal of Biological Chemistry, 271, 1916-1924.

Neethirajan. S, \& Jayas, D. S. (2011). Nanotechnology for the food and bioprocessing industries. Food and Bioprocess Technology. 4 (1), 39-47.

Newman, A. W., \& Kwok, D. Y. (1999). Contact angle measurement and contact angle interpretation. Advances in Colloid and Interface Science, 81, 167-249. 
Nicolaï, B. M., Verlinden, B. E., Desmet, M., Saevels, S., Saeys, W., Theron, K., et al. (2008). Time-resolved and continuous wave NIR reflectance spectroscopy to predict soluble solids content and firmness of pear. Postharvest Biology and Technology, 47, 68-74.

Olivas, G. I., \& Barbosa-Cánovas, G. V. (2005). Edible coatings for fresh-cut fruits. Critical Reviews in Food Science and Nutrition, 45, 657-670.

Olivas, G. I., Mattinson, D. S., \& Barbosa-Cánovas, G. V. (2007). Alginate coatings for preservation of minimally processed 'Gala' apples. Postharvest Biology and Technology, 45, 89-96.

Oliveira, M. E. B., Bastos, M. S. R., Feitosa, T., Branco, M. A. A. C., \& Silva, M. G. G. (1999). Avaliação de parâmetros de qualidade físico-químicos de polpas congeladas de acerola, cajá e caju. Ciencia e Tecnologia de Alimentos, 19(3), 326-332.

Oms-Oliu, G., Soliva-Fortuny, R., \& Martín-Belloso, O. (2008). Edible coatings with antibrowning agents to maintain sensory quality and antioxidant properties of fresh-cut pears. Postharvest Biology and Technology, 50, 87-94.

Park, S. I., Daeschel, M. A., \& Zhao, Y. (2004). Functional properties of antimicrobial lysozyme-chitosan composite films. Journal of Food Science, 69(8), 215-221.

Reynaers, H. (2003). Light scattering study of polyelectrolyte polysaccharides-The carrageenans. Fibres \& Textile in Eastern Europe, 5(11), 88-96.

Ribeiro, C., Vicente, A. A., Teixeira, J. A., \& Miranda, C. (2007). Optimization of edible coating composition to retard strawberry fruit senescence. Postharvest Biology and Technology, 44, 63-70.

Rojas-Graü, M. A., Soliva-Fortuny, R., \& Martín-Belloso, O. (2009). Edible coatings to incorporate active ingredients to freshcut fruits: A review. Trends in Food Science and Technology, 20, 438-447.

Schoeler, B., Delorme, N., Doench, I., Sukhorukov, G. B., Fery, A., \& Glinel, K. (2006). Polyelectrolyte films based on polysaccharides of different conformations: Effects on multilayer structure and mechanical properties. Biomacromolecules, 7(6), 2065-2071.

Silva, F. J. P., Gomes, M. H., Fidalgo, F., Rodrigues, J., \& Almeida, D. P. F. (2010). Antioxidant properties and fruit quality during long-term storage of "Rocha" pear: Effects of maturity and storage conditions. Journal of Food Quality, 33, 1-20.

Souza, M. P., Cerqueira, M. A., Souza, B. W. S., Teixeira, J. A., Porto, A. L. F., Vicente, A. A., et al. (2010). Polysaccharide from Anacardium occidentale L. tree gum (Policaju) as a coating for Tommy Atkins mangoes. Chemical Papers, 64(4), 475-481.

Su, T. J., Lu, J. R., Thomas, R. K., Cui, Z. F., \& Penfold, J. (1998). The effect of solution $\mathrm{pH}$ on the structure of lysozyme layers adsorbed at the silica-water interface studied by neutron reflection. Langmuir, 14, 438-445.

$\mathrm{Su}, \mathrm{Y} .$, \& Li, C. (2008). Stable multilayer thin films composed of gold nanopaticles and lysosyme. Applied Surface Science, 254(7), 2003-2008.

Toğrul, H., \& Arslan, N. (2004). Extending shelf-life of peach and pear by using CMC from sugar beet pulp cellulose as a hydrophilic polymer in emulsions. Food Hydrocolloids, 18, 215-226.

Yoo, D., Shiratori, S. S., \& Rubner, M. F. (1998). Controlling bilayer composition and surface wettability of sequentially adsorbed multilayers of weak polyelectrolytes. Macromolecules, 31, 43094318. 